\title{
COVID- 19 pandemisi sürecinde kız öğrencilerin maske kullanımlarının beden imajları ve beden saygıları üzerine etkisi
}

The effect of female students' use of masks on their body image and body esteem during the COVID-19 pandemic

\author{
iD Gülçin Nacar ${ }^{1}$, iD Seher Çevik Aktura ${ }^{2}$
}

${ }^{1}$ İnönü Üniversitesi, Hemşirelik Fakültesi, Doğum-Kadın Sağlığı ve Hastalıkları Hemşireliği Anabilim Dalı, Malatya, Türkiye ${ }^{2}$ Inönü Üniversitesi, Hemşirelik Fakültesi, Hemşirelik Anabilim Dalı, Malatya, Türkiye

\section{ÖZET}

Amaç: Araştırmanın amacı COVID-19 pandemisi sürecinde kız öğrencilerin maske kullanımlarının beden imajları ve beden saygıları üzerine etkisinin belirlenmesidir.

Yöntem: Araştırma tanımlayıcı ve ilişki arayıcı olarak yapılmıştır. Araştırmanın evrenini Türkiye'nin doğusunda bulunan bir üniversitenin hemşirelik fakültesinin $620 \mathrm{kız}$ öğrencisi oluşturmuştur. Araştırmada örneklem seçimine gidilmeden bütün evrene ulaşılmaya çalışılmış ve araştırma 337 öğrenci ile tamamlanmıştır. Veriler araştırmacılar tarafından oluşturulan Kişisel tanıtım formu, Vücut Algısı Ölçeği ve Rosenberg Benlik Saygısı Ölçeği ile toplanmıştır. Verilerin değerlendirilmesinde, tanımlayıcı istatistik, bağımsız gruplarda t testi, ki-kare testi ve Logistic Regression analizi kullanılmıştır.

Bulgular: Araştırmada yapılan Lojistik Regresyon analizi sonucunda, COVID-19 pandemisinde maske kullanımı nedeniyle; makyaj yapma sıklığı azalanların 0.46 kat, daha az sosyalleşenlerin 0.39 kat ve benlik saygısı düşük olanların 0.95 kat daha olumsuz dış görünüş algısına sahip olduğu saptanmıştır.

Sonuçlar: Araştırma sonucunda makyaj yapma sıklığı ve sosyalleşme düzeyinin azalması ile düşük benlik saygısının kız öğrencilerde maske kullanımına ilişkin olumsuz dış görünüş algısına neden olduğu bulunmuştur. COVID-19 pandemisi sürecinde özel bir grup olan üniversite öğrencilerinin dikkatle ele alınması gereklidir.

Anahtar kelimeler: beden imajı; COVID-19 virüs; hemşirelik öğrencileri; maskeler

\section{ABSTRACT}

Aim: The aim of the study is to determine the effect of female students' use of masks on their body image and body esteem during the COVID-19 pandemic.

Methods: The research has been conducted as a descriptive and relationship seeker. The universe of study of a college's nursing faculty in the east of Turkey has created 620 female students. The whole population was tried to be reached without choosing a sample in the study and the research was completed with 337 students. The data were collected with the Personal introduction form, Body Perception Scale and Rosenberg's Self-esteem Scale created by the researchers. Descriptive statistics, independent groups t test, Chi-square test and Logistic Regression analysis were used to evaluate the data.

Results: As a result of the Logistic Regression analysis conducted in the research, due to the use of masks in the COVID-19 pandemic; It was determined that those who decreased the frequency of wearing make-up had 0.46 times more negative appearance perception, those who socialized less than 0.39 times and those with low self-esteem had 0.95 times more negative appearance perception.

Conclusion: As a result of the research, it was found that the frequency of wearing make-up and the decrease in the level of socialization, and low self-esteem caused negative external appearance perception in female students about using masks. During the COVID-19 pandemic, university students, a special group, need to be handled carefully.

Keywords: body image; COVID-19 virus; nursing students; masks

\section{Giriş}

Bir yılı aşkın süredir dünyanın karşı karşıya olduğu COVID19 salgını bireyin hayatını her yönden etkilemeye devam ediyor. Eğitim ile ilgili aksaklıklar devam ederken insanlar evlerinden çalışmakta, yemek ve eğlence hizmeti veren işletmelerin bir kısmı kapalıyken bir kısmında ciddi kısıtlamalar mevcuttur (Howard ve ark., 2021; Scheid, Lupien, Ford \& West, 2020). COVID-19 virüsünün bulaşmasına ilişkin her gün yeni bilgiler elde edilmektedir (WHO, 2020). COVID-19 esas olarak bir solunum sistemi hastalığıdır ve çok hafif, solunum dışı semptomlardan, şiddetli akut solunum yolu sıkıntıları, organ disfonksiyonlu sepsis ve hatta ölüme kadar değişen sonuçlara yol açabilmektedir. Bununla birlikte hiçbir belirti vermeyen hastalar da mevcuttur (Velavan \& Meyer, 2020). Mevcut kanıtlara göre, COVID-19 virüsü öncelikle insanlar arasında solunum damlacıkları ve temas yoluyla bulaşır.
Damlacık iletimi, enfekte bir kişiyle yakın temas halinde olunduğunda (1 metre içinde) ve potansiyel olarak enfektif solunum damlacıklarına maruz kalındığında meydana gelir; örneğin, öksürme, hapşırma veya çok yakın kişisel temas yoluyla bulaşır (Mahase, 2020; Yuki, Fujiogi \& Koutsogiannaki, 2020). Bulaşma, enfekte kişinin yakın çevresindeki eşyalardan da meydana gelebilir. Bu bulaşmayı önlemek ya da en aza indirmek amacıyla çoğu gelişmiş ülkenin yetkilileri bu süreçte halka; sosyal mesafeyi korumak, maske kullanmak ve el yıkamak şeklinde 3 temel öneride bulunmuştur (Wiersinga, Rhodes, Cheng, Peacock \& Prescott, 2020).

Vaka sayısının artması ile beraber maske kullanımı birçok kurumda zorunlu hale gelmiştir. Maske kullanımındaki temel amaç solunum yoluyla ortaya çıkan partiküllerin havaya saçılmasını ve diğer insanlara geçişini önlemektir (Feng ve ark., 2020; Li, Liu, Li, Qian \& Dai, 2020). Öneri ve 
zorunluluklarla beraber, filtreleme yeteneklerini etkileyen farklı malzemelerden ve tasarımlardan oluşan maskeler kullanılmaya başlanmıştır (Greenhalgh, Schmid, Czypionka, Bassler \& Gruer, 2020; Lepelletier ve ark., 2020). Maskenin koruyucu etkilerinin yanı sıra nefes alıp vermede zorlaşmaya, cilt problemlerine, sıcaklık artışına ve estetik kaygılara sebep olabilmektedir (Eikenberry ve ark., 2020; Feng ve ark., 2020). Özellikle medyanın etkisi ile birlikte insanların dış görünüşleri ile ilgili estetik kaygıları giderek artmaktadır (Uğurlu, 2015). İlk çağlardan itibaren insanlar dış görünüşlerine önem vermişlerdir. Çünkü olumlu beden algısının ve benlik saygısının bireylerin özgüvenini ve sosyalliğini arttırdığı, toplum karşısında kendilerini daha rahat ifade ettikleri ve arkadaş grubu edinmede etkili olduğu çalışmalarla ortaya konmuştur (Ahmed, Nayeem Siddiqua, Alam \& Griffiths, 2021; Erdoğanoğlu, Solak, Şimşek \& Erdil, 2019; Haspolat \& Kağan, 2017; Ngo, VanderLaan \& Aitken, 2020; Tütüncü \& Erdoğan, 2015). Özellikle gençlik dönemi bireylerin kimlik arayışında olduğu, dış görünüşün ve arkadaş grubu içerisinde varlık göstermenin önemli olduğu bir dönemdir. Genellikle genç grup içerisine giren üniversite öğrencilerinin bedenlerine ilişkin görüşleri ve benlik saygıları şüphesiz benlik kavramlarına ve kimliklerine katkıda bulunur (Šmídová, Švancara, Andrýsková \& Šimůnek, 2018). Buradan hareketle yüzün büyük bir kısmını kapatan maskenin, COVID-19 pandemisi sürecinde kız öğrencilerin beden imajları ve beden saygıları üzerine etkisini incelemektir.

\section{Yöntem}

Araştırma tanımlayıcı ve ilişki arayıcı olarak yapılmıştır. Araştırmanın evrenini Türkiye'nin doğusunda bulunan bir üniversitenin hemşirelik fakültesinin kı öğrencileri oluşturmuştur. Fakültenin yaklaşık 620 kız öğrencisi bulunmaktadır. Araştırmada örneklem seçimine gidilmeden bütün evrene ulaşılmaya çalışılmış ve araştırma 337 öğrenci ile tamamlanmıştır. Araştırmada 203 öğrenci e-posta ile gönderilen araştırma formuna geri dönüş yapmadığı için, 80 öğrenci ise araştırmaya dahil edilme kriterlerini karşılamadığı (Türkçeyi yeterli düzeyde kullanamayan yabancı uyruklu öğrenciler ( $n=76)$, psikiyatrik hastalık tanısı olan öğrenciler $(n=4))$ için çalışma dışı bırakılmıştır.

Öğrencilerin araştırmaya dahil edilme kriterleri; herhangi bir iletişim engelinin bulunmaması ve herhangi bir psikiyatrik tanısının olmamasıdır. Öğrencilerin araştırmadan dışlanma kriteri ise, formların eksik ya da yanlış doldurulmasıdır.

\section{Verilerin toplanması}

Araştırmanın verileri 30 Şubat - 30 Mart 2021 tarihleri arasında, online form aracılığıyla öğrencilerden e-posta yoluyla toplanmıştır. Veriler araştırmacılar tarafından oluşturulan Kişisel tanıtım formu, Vücut Algısı Ölçeği ve Rosenberg Benlik Saygısı Ölçeği ile toplanmıştır. Araştırma formlarını doldurmak yaklaşık 10 dakika sürmektedir.

\section{Kişisel tanıtım formu}

Form, araştırma kapsamına alınan öğrencilerin sosyodemografik özellikleri, maske kullanımına ilişkin özellikleri ve makyaj yapma alışkanlıklarını belirlemeye yönelik özelliklerini sorgulamak amacıyla araştırmacılar tarafından oluşturuldu. Formda toplam 12 soru bulunmaktadır.

\section{Vücut Algısı Ölçeği}

Secord ve Jourad (1953) tarafından geliştirilen ölçeğin Türkçe geçerlik ve güvenirliği Hovardaoğlu (1993) tarafından yapılmıştır. Ölçek 40 maddeden oluşmakta olup her madde 1-5 (hiç beğenmiyorum, beğenmiyorum, kararsızım, beğeniyorum, çok beğeniyorum) arasında puanlanmaktadır. Ölçekten en az 40, en fazla 200 puan alınmaktadır. Ölçekten alınan puanın yükselmesi olumlu vücut algısını ifade etmektedir. Ölçeğin orijinal Cronbach's alfa değeri 0.91'dir (Hovardaoğlu, 1993; Secord \& Jourard, 1953). Bu çalışmada ise ölçeğin Cronbach's alfa değeri 0.93 olarak bulunmuştur.

\section{Rosenberg Benlik Saygısı Ölçeği}

Rosenberg (1963) tarafından geliştirilen ölçeğin Türkçe geçerlilik ve güvenirliği Çuhadaroğlu (1986) tarafından yapılmıştır. Ölçekte 12 alt boyut yer almakta olup toplam 63 maddeden oluşmaktadır. Rosenberg alt ölçeklerin ayrı ayrı kullanılabileceğini belirtmiştir. Araştırmanın amacı doğrultusunda benlik saygısını ölçmeye yönelik ölçeğin ilk '10' maddesi kullanılmıştır. Ölçek 4'lü likert olup, "Çok Doğru”, "Doğru", "Yanlış" ve "Çok Yanlış" olacak şeklinde 0-3 arasında puanlanmaktadır. Ölçekteki 3, 5, 8, 9, 10. sorular ters kodlanmıştır. Ölçekten 0-30 arasında puan alınabilmekte olup, 15-25 arası puan yeterli benlik saygısını, 15 puanın altı ise düşük benlik saygısını ifade etmektedir. Ölçeğin orijinal Cronbach's alfa değerleri 0.77 ile 0.88 arasında değişmektedir (Çuhadaroğlu, 1986). Bu çalışmada ise ölçeğin Cronbach's alfa değeri 0.87 'dir.

\section{Araştırmanın etik yönü}

Araştırmaya başlamadan önce, İnönü Üniversitesi Hemşirelik Fakültesi'nden yazılı izin ve İnönü Üniversitesi Sağlık Bilimleri Bilimsel Araştırma ve Yayın Etik Kurulu'ndan (Karar no: 2021/1624) etik onam alınmıştır. Ayrıca araştırmaya alınan öğrencilerden gönüllü onam alınmıştır.

\section{İstatistiksel Analiz}

Veriler SPSS 23.0 istatistik paket programı kullanılarak analiz edilmiştir. Verilerin değerlendirilmesinde, tanımlayıcı istatistik, bağımsız gruplarda t testi ki-kare testi ve Lojistik Regresyon analizi kullanılmıştır. Sonuçlar \%95'lik güven aralığında, anlamlılık p<0.05 düzeyinde değerlendirilmiştir.

\section{Bulgular}

Tablo 1. Öğrencilerin maske kullanımının dış görünüşte oluşturduğu değişiklik ile sosyo-demografik özelliklerinin karşılaştırılması $(\mathrm{n}=337)$

\begin{tabular}{|c|c|c|c|}
\hline \multirow{2}{*}{$\begin{array}{l}\text { Sosyo-demografik } \\
\text { özellikler }\end{array}$} & \multicolumn{2}{|c|}{$\begin{array}{c}\text { Maske kullanımının dış } \\
\text { görünüşte oluşturduğu } \\
\text { değişiklik }\end{array}$} & \multirow[b]{2}{*}{$\begin{array}{l}\text { Toplam } \\
\overline{\mathbf{x}} \pm \mathbf{S S}\end{array}$} \\
\hline & $\begin{array}{c}\text { Olumlu } \\
\overline{\mathbf{x}} \pm \mathbf{S S}\end{array}$ & $\begin{array}{c}\text { Olumsuz } \\
\bar{x} \pm S S\end{array}$ & \\
\hline $\begin{array}{l}\text { Yaş ( } \overline{\mathbf{x}} \mathbf{S S S}) \\
t / p\end{array}$ & \multicolumn{2}{|c|}{$2.27 / 0.025$} & $20.77 \pm 2.34$ \\
\hline $\begin{array}{l}\text { BKI } \\
t / p\end{array}$ & $\begin{array}{r}21.34 \pm 3.32 \\
-1.41 \\
\end{array}$ & $\begin{array}{l}22.77 \pm 4.77 \\
0.160\end{array}$ & $22.36 \pm 12.63$ \\
\hline & n (\%) & $\mathbf{n}(\%)$ & n (\%) \\
\hline $\begin{array}{l}\text { Gelir durumu } \\
\text { Gelir giderden az } \\
\text { Gelir gidere eşit } \\
\text { Gelir giderden fazla } \\
X^{2} / p\end{array}$ & $\begin{array}{c}14(4.2) \\
52(15.4) \\
29(8.6) \\
0.09\end{array}$ & $\begin{array}{c}33(9.8) \\
132(39.2) \\
77(22.8) \\
0.953\end{array}$ & $\begin{array}{c}47(13.9) \\
184(54.6) \\
106(31.5)\end{array}$ \\
\hline \multicolumn{3}{|c|}{ COVID-19 pandemisinin makyaj yapma sıklığını etkileme durumu } & \\
\hline $\begin{array}{l}\text { Makyaj yapma sıklığının } \\
\text { azalması } \\
\text { Değişikliğin olmaması } \\
X^{2} / p\end{array}$ & $\begin{array}{l}28(8.3) \\
67(19.9) \\
14.5\end{array}$ & $\begin{array}{r}127(37.7) \\
115(34.1) \\
0.001\end{array}$ & $\begin{array}{l}155(46.0) \\
182(54.0)\end{array}$ \\
\hline $\begin{array}{l}\text { Maske kullanırken ruj sürme d } \\
\text { Evet } \\
\text { Hayır } \\
X^{2} / p\end{array}$ & $\begin{array}{l}\text { urumu } \\
58(17.2) \\
37(11.0) \\
4.70\end{array}$ & $\begin{array}{l}116(34.4) \\
126(37.4) \\
0.030\end{array}$ & $\begin{array}{l}174(51.6) \\
163(48.4)\end{array}$ \\
\hline $\begin{array}{l}\text { Maske kullanırken ruj sürme n } \\
\text { Kendini daha iyi hissetmek } \\
\text { Dudaklarını nemlendirmek } \\
\text { Maske kullanımına ara vermek }\end{array}$ & edeni & & $\begin{array}{l}73(42.0) \\
63(36.2) \\
38(21.8) \\
\end{array}$ \\
\hline \multicolumn{4}{|c|}{ Maske kullanımının sosyal hayatı etkileme durumu } \\
\hline $\begin{array}{l}\text { Daha az sosyalleşme } \\
\text { Her zamanki kadar sosyalleşme }\end{array}$ & $\begin{array}{l}74(22.0) \\
21(6.2)\end{array}$ & $\begin{array}{l}132(39.2) \\
110(32.6)\end{array}$ & $\begin{array}{l}206(61.1) \\
131(38.9)\end{array}$ \\
\hline$X^{2} / p$ & \multicolumn{2}{|c|}{$15.65 / 0.001$} & \\
\hline Toplam & 95 (28.2) & $242(71.8)$ & $337(100.0)$ \\
\hline
\end{tabular}


Tablo 2. Öğrencilerin maske kullanımının dış görünüşte oluşturduğu değişiklik ile sosyo-demografik özelliklerinin karşılaştırılması $(n=337)$

\begin{tabular}{|c|c|c|c|}
\hline & \multicolumn{2}{|c|}{$\begin{array}{c}\text { Maske kullanımının dış } \\
\text { görünüşte oluşturduğu } \\
\text { değişiklik }\end{array}$} & \multirow[b]{2}{*}{$t / p$} \\
\hline & $\begin{array}{c}\text { Olumlu } \\
\overline{\mathbf{x}} \pm S S\end{array}$ & $\begin{array}{c}\text { Olumsuz } \\
\overline{\mathbf{x}} \pm S S\end{array}$ & \\
\hline $\begin{array}{l}\text { Vücut Algısı } \\
\text { Ölçeği }\end{array}$ & $141.23 \pm 22.75$ & $146.57 \pm 23.58$ & $\begin{array}{c}-1.918 / \\
0.057\end{array}$ \\
\hline $\begin{array}{l}\text { Rosenberg Benlik } \\
\text { Saygısı Ölçeği }\end{array}$ & $9.83 \pm 6.54$ & $8.13 \pm 6.33$ & $\begin{array}{c}2.166 / \\
0.032\end{array}$ \\
\hline
\end{tabular}

t: Independent student test

Araştırmada öğrencilerin yaş ortalamasının $20.77 \pm 2.34$, BKI ortalamasının $22.36 \pm 12.63$ ve $\% 54.6$ 'sının gelirinin giderine denk olduğu saptanmıştır. Öğrencilerin \%71.8'i maske kullanımının dış görünüşünü olumsuz etkilediğini, \%46.0'sı COVID-19 pandemisinin makyaj yapma sıklığını azalttığını, \%51.6'sı maske kullanırken ruj sürdüğünü ve $\% 61.1$ 'i maske kullanımının sosyal hayatını olumsuz etkilediğini belirtmiştir. Öğrencilerin maske kullanırken ruj sürme nedenleri incelendiğinde; öğrencilerin \%27.3'ü kendini daha iyi hissettiği, \%22.3'ü dudaklarını nemlendirdiği ve \%13.1'i maske kullanımına ara verdiği için ruj sürdüğünü belirtmiştir. Yaşı daha küçük olanların, maske nedeniyle makyaj yapma sıklığı azalanların, maske kullanırken ruj sürmeyenlerin ve daha az sosyalleşenlerin maske kullanımının dış görünüşlerini olumsuz etkilediğini belirtmiştir ( $p<0.05$; Tablo 1).

Araştırmada maske kullanımının dış görünüşte oluşturduğu değişiklik ile vücut algısı arasında anlamlı bir ilişki bulunmamıştır $(p>0.05)$. Maske kullanımının dış görünüşünü olumsuz etkilediğini düşünen öğrencilerin benlik saygısının daha düşük olduğu saptanmıştır $(p<0.05$; Tablo 2$)$.

Maske kullanımının dış görünüşte olumlu ve olumsuz değişiklik oluşturduğunu düşünen öğrenciler arasında fark olduğu saptanan değişkenler ile kurulan Binary Lojistik regresyon modelinde; maske kullanımının dış görünüşte olumlu ve olumsuz değişiklik yapma durumu bağımlı değişken, yaş, COVID-19 pandemisinin makyaj yapma sıklığını etkileme durumu, maske kullanırken ruj sürme durumu, maske kullanımının sosyal hayatı etkileme durumu ve RBSÖ bağımsız değişken olarak alınmıştır. Binary lojistik regresyon analizinde model seçim yöntemlerinden tüm değişkenlere ait kat sayıların önemliliğinin tek adımda değerlendirildiği "Enter" yöntemi kullanılmıştır. Değişkenlere ait parametre tahminleri $(\beta)$, standart hataları (se), Wald istatistikleri $(\mathrm{W})$, serbestlik dereceleri (sd), odds oranları (Exp (ß)) ve güven aralıklarına (\%95 Cl) ait bilgiler Tablo 3'de verilmiştir. Binary Lojistik Regresyon sonucunda, COVID-19 pandemisinde maske kullanımı nedeniyle; makyaj yapma sıklığı azalanların 0.46 kat, daha az sosyalleşenlerin 0.39 kat ve benlik saygısı düşük olanların 0.95 kat daha olumsuz dış görünüş algısına sahip olduğu saptanmıştır (Tablo 3).

\section{Tartışma}

Tıp dünyasının aşina olduğu cerrahi bir malzeme olan maske, COVID-19 pandemisi nedeniyle günlük yaşamımızın bir parçası haline gelmiştir (Kaya, 2020). Maske kullanımı sağlık açısından COVID-19 bulaşını önlemeye yönelik bir bariyer iken; sosyal, kültürel ve psikolojk olarak pek çok anlam ifade etmektedir. Hava kirliliğinin çok fazla olduğu ülkelerde maske kullanımı olağan karşılanırken, pek çok ülkede maske kullanımı kabul görmemektedir. Çeşitli kültürde maske yüzü gizleme ve duyguları saklama ile ilişkilendirilmektedir (Şener Pedgley, 2021). Yüzün büyük bir kısmını kapatan maskenin, dış görünüşün oldukça önemsendiği genç grup için estetik kaygılara neden olabileceği düşünülmektedir (Feng ve ark., 2020; Šmídová ve ark., 2018). Gençlik döneminde gelişen benlik saygısı ve vücut algısı ile dış görüşüne verilen anlam arasında karşılıklı bir ilişki bulunmaktadır. Gençlerin zihninde şekillendirdiği beden görüşünü ile gerçek görünüşü uyuşmadığında olumsuz vücut algısı geliştirmektedir. Gençlerde olumsuz vücut algısı, benlik saygısının düşmesine neden olabilmektedir (Çırak \& Özdemir, 2015; Šmídová ve ark., 2018). Üniversite öğrencilerinde maske kullanımı ile vücut algısı ve benlik saygısını birlikte inceleyen çalışmaya rastlanmamakla beraber, COVID-19 pandemisi sürecinde kız öğrencilerin maske kullanımlarının beden imajları ve benlik saygıları üzerine etkisini belirlemek amacıyla yapılan çalışmanın bulguları aşağıda mevcut literatür ile tartışıımıştır.

Araştırmada COVID-19 pandemisinde maske kullanımı nedeniyle, makyaj yapma sıklığı azalanların 0.46 kat daha olumsuz dış görünüş algısına sahip olduğu saptanmıştır. Yüz, vücudun sosyalleşmede en aktif kullanılan kısmıdır. Hem dış görünüşü yansıtan en önemli bölüm hem de jest ve mimiklerin en fazla kullanıldığı iletişim aracıdır (Okkay \& Bal, 2021). Özellikle gençler için yüz, beden imajının en önemli parçasıdır (Šmídová ve ark., 2018). Bu nedenle gençler, makyaj gibi estetik uygulamalar ile akranları arasında kabul görmek için çabalar. Bulgumuz literatürü desteklemektedir.

Sosyal ilişkilerimiz COVID-19 pandemisi nedeniyle önemli ölçüde etkilenmiştir. Virüs bulaşını önlemek için sosyal mesafe ve maske kullanımı neredeyse tüm dünyada zorunlu hale gelmiştir (Goh, Tan, Bhartendu, Ong \& Sharma, 2020). Maske kullanımı virüs bulaşını önleyen önemli bir kalkan olmakla birlikte, dış görünüşte radikal bir değişikliğe neden olmaktadır. Maske kullanımı yüz yüze iletişimi de sekteye uğratmaktadır. Sesi boğmakta ve farkında olmadan iletişim kurmakta sıklıkla kullandığımız yüz ifadelerinin çoğunun görünmesine engel olmaktadır (Mheidly, Fares, Zalzale \& Fares, 2020). Bu durumun gençlerin daha az sosyalleşmesine neden olacağı düşülmektedir. Nitekim araştırmada daha az sosyalleşenlerin maske kullanımı nedeniyle 0.39 kat daha olumsuz dış görünüş algısına sahip olduğu saptanmıştır.

Benlik saygısı, bireyin kendini değerlendirmesi sonucu varmış olduğu olumlu ya da olumsuz düşünce bütünüdür. Benlik saygısı gençlik döneminde geliştirilen ve birçok faktörden etkilenen bir olgudur. Beden saygısı, yeni durumlar karşısındaki reaksiyonların belirleyicisi olabileceği gibi, meydana gelen ani bedensel değişiklikler de gençlerin beden saygısını olumsuz yönde etkileme riskine sahiptir (Eriş \& İkiz, 2013). Bu araştırmada da benlik saygısı düşük olanların maske kullanımı nedeniyle 0.95 kat daha olumsuz dış görünüş algısına sahip olduğu saptanmıştır.

\section{Sonuç ve Öneriler}

Araştırmada makyaj yapma sıklığı ve sosyalleşme düzeyinin azalması ile düşük benlik saygısının kız öğrencilerde maske kullanımına ilişkin olumsuz dış görünüş algısına neden olduğu saptanmıştır. COVID-19 pandemisi nedeniyle aniden ortaya çıkan önlemlerin, kısıtlamaların ve karantina sürecinin tüm yaş gruplarında önemli etkisi 
Tablo 3. Maske kullanımının dış görünüşte oluşturduğu değişiklik ile ilişkili risk faktörlerinin ileri analizi ${ }^{\star}$

\begin{tabular}{|c|c|c|c|c|c|c|}
\hline Risk Faktörleri & $\beta$ & SE & df & $\mathbf{p}$ & OR & $95 \% \mathrm{Cl}$ \\
\hline Yaş & -0.105 & 0.054 & 1 & 0.050 & 0.90 & $0.810-1.000$ \\
\hline \multicolumn{7}{|c|}{$\begin{array}{l}\text { COVID-19 pandemisinin makyaj yapma sıklığını etkileme } \\
\text { durumu (referans: değişikliğin olmaması) }\end{array}$} \\
\hline Makyaj yapma sıklığının azalması & -0.784 & 0.28 & 1 & 0.005 & 0.46 & $0.265-0.788$ \\
\hline \multicolumn{7}{|c|}{ Maske kullanırken ruj sürme durumu (referans: hayır) } \\
\hline Evet & -0.358 & 0.266 & 1 & 0.178 & 0.70 & $0.415-1.177$ \\
\hline \multicolumn{7}{|c|}{$\begin{array}{l}\text { Maske kullanımının sosyal hayatı etkileme durumu } \\
\text { (referans: Her zamanki kadar sosyalleşme) }\end{array}$} \\
\hline Daha az sosyalleşme & -0.951 & 0.289 & 1 & 0.001 & 0.39 & $0.219-0.681$ \\
\hline Rosenberg Benlik Saygısı Ölçeği & -0.051 & 0.020 & 1 & 0.010 & 0.95 & $0.915-0.988$ \\
\hline
\end{tabular}

*Logistic Regression, SE: Standard Error, df: Degree of freedom, OR: Odd's ratio, Cl: Confidence interval

bulunmakla birlikte, kimlik kazanma süreci olan gençler üzerindeki etkisi dikkatle incelenmelidir. Hemşire eğitimcilerin, kız üniversite öğrencilerinin pandemi sürecinde maske kullanımı nedeniyle sahip olduğu olumsuz dış görünüş algısının ortadan kaldırılması için önlemler almalıdır. Öncelikle pandemi sürecinin geçici bir dönem olduğu vurgulanmalıdır. Özellikle sağlık disiplini üyesi olan öğrencilerin pandemi sürecinde kaygılarının daha yüksek olabileceği gözden kaçırılmamalıdır. Öğrencilerin ev ortamında yapılabilecek çeşitli hobilere, evde spor yapmaya yönlendirilmesi, mesleki yaşama hazırlayıcı online eğitimlerin düzenlenmesi ve sağlıklı bir beden algısı ve benlik saygısı geliştirmeye yönelik seçmeli derslerin oluşturulması önerilmektedir.

\section{Çıkar Çatışması}

Yazarlar çıkar çatışması bildirmemişlerdir.

\section{Teşekkür} ederiz.

Araştırmaya katılmayı kabul eden öğrencilerimize teşekkür

\section{Finansal Destek}

Araştırma, herhangi bir fon ile desteklenmemiştir.

\section{Etik Komite Onay}

İnönü Üniversitesi Sağlık Bilimleri Girişimsel Olmayan Klinik Araştırmalar Etik Kurulu'ndan (2021/1624) onay alınmıştır.

\section{Bilgilendirilmiş Onam}

Öğrencilerden sözlü onay alınmıştır.

\section{Hakem Değerlendirmesi}

Dış bağımsız.

\section{Yazar Katkıları}

G.N.: Fikir/Tasarım, Verilerin Toplanması, İstatistiksel Analiz, Makalenin Yazımı, Kritik Okuma.

S.Ç.A.: Fikir/Tasarım, Literatür Taraması, Verilerin Toplanması, Makalenin Yazımı, Kritik Okuma.

\section{Kaynaklar}

Ahmed, O., Nayeem Siddiqua, S. J., Alam, N., \& Griffiths, M. D. (2021). The mediating role of problematic social media use in the relationship between social avoidance/distress and self-esteem. $\begin{array}{llr}\text { Technology in } & \text { Society, } & \text { 1-7. }\end{array}$ https://doi.org/10.1016/j.techsoc.2020.101485

Çırak, R., \& Özdemir, F. (2015). Adölesan gebelerde beden imajı algısının belirlenmesi. Anadolu Hemşirelik ve Sağlık Bilimleri Dergisi, 18(3), 214-221.

Çuhadaroğlu, F. (1986). Adolesanlarda benlik saygısı. (Uzmanlık Tezi) Hacettepe Üniversitesi Tıp Fakültesi Psikiyatri Anabilim Dalı, Ankara.

Eikenberry, S. E., Mancuso, M., Iboi, E., Phan, T., Eikenberry, K., Kuang, Y., ... Gumel, A. B. (2020). To mask or not to mask: Modeling the potential for face mask use by the general public to curtail the COVID-19 pandemic. Infectious Disease Modelling, 5, 293-308. https://doi.org/10.1016/j.idm.2020.04.001

Erdoğanoğlu, Y., Solak, B. N., Şimşek, M., \& Erdil, M. E. (2019). Erken ve geç evre osteoartritli hastalarda ağrı şiddeti ile beden algısı, benlik saygısı, depresyon ve fonksiyonel düzey arasındaki ilişkinin incelenmesi: pilot çalışma. Journal of Exercise Therapy and Rehabilitation, 6(3), 188-194.

Eriş, Y., \& Ikiz, F. E. (2013). The relation between self-esteem and social anxiety levels of adolescents and the effects of personal variables. Turkish Studies - International Periodical For The Languages, Literature and History of Turkish or Turkic, 8, 179193.

Feng, S., Shen, C., Xia, N., Song, W., Fan, M., \& Cowling, B. J. (2020, May). Rational use of face masks in the COVID-19 pandemic. The Lancet Respiratory Medicine, 8, 434-436. https://doi.org/10.1016/S2213-2600(20)30134-X

Goh, Y., Tan, B. Y. Q., Bhartendu, C., Ong, J. J. Y., \& Sharma, V. K. (2020). The face mask: How a real protection becomes a psychological symbol during Covid-19? Brain, Behavior, and Immunity, 88, 1-5. https://doi.org/10.1016/j.bbi.2020.05.060

Greenhalgh, T., Schmid, M. B., Czypionka, T., Bassler, D., \& Gruer, L. (2020). Face masks for the public during the Covid-19 crisis. The BMJ, 369. https://doi.org/10.1136/bmj.m1435

Haspolat, N. K., \& Kağan, M. (2017). Sosyal fobinin yordayıcıları olarak beden imajı ve benlik saygısı. Erzincan Üniversitesi Eğitim $\begin{array}{lll}\text { Fakültesi Dergisi, } & 19(2), & 139-152 .\end{array}$ https://doi.org/10.17556/erziefd.322327

Hovardaoğlu S. (1993). Vücut Algısı Ölçeği. Psikiyatri, Psikoloji, Psikofarmakoloji (3P) Dergisi, 1(1), 26.

Howard, J., Huang, A., Li, Z., Tufekci, Z., Zdimal, V., van der Westhuizen, H. M., ... Rimoin, A. W. (2021). An evidence review of face masks against COVID-19. Proceedings of the National Academy of Sciences of the United States of America, 118(4), 112. https://doi.org/10.1073/pnas.2014564118

Kaya, İ. (2020). Existing with a mask and the mask of medicine as a 
practice of biopolitical. Turkish Journal of Religious Studies, 20(2), 593-613.

Şener Pedgley, B. (2021). Maskenin maskesini düşürmek. Arredamento Mimarlik, 345, 94-97. https://hdl.handle.net/11511/89405

Šmídová, S., Švancara, J., Andrýsková, L., \& Šimůnek, J. (2018). Adolescent body image: results of czech elspac study. Cent Eur J Public Health, 26(1), 60-64. https://doi.org/10.21101/cejph.a4930

Tütüncü, İ., \& Erdoğan, Ö. (2015). Studying the relationship among body image, eating attitude and the level of building close relationshıp of university students. Internatıonal Refereed Academic Journal of Sports, 17, 89-89. https://doi.org/10.17363/sstb.20151714052

Uğurlu, Ö. (2015). Kadının benlik sunumunun güncel bir aracı olarak sosyal ağlar bir tasarım unsuru: "Kusursuzlaştırma." Sosyal Bilimler Dergisi, 2014(19), 231-248. https://doi.org/10.12780/uusbd.29677

Velavan, T. P., \& Meyer, C. G. (2020). The COVID-19 epidemic. Tropical Medicine and International Health, 25, 278-280. https://doi.org/10.1111/tmi.13383

WHO. (2020). Global epidemiological situation WHO. Retrieved from https://www.who.int/docs/default-source/coronaviruse/situationreports/20200907-weekly-epi update 4.pdf?sfvrsn=f5f607ee_2\%0Ahttps://www.who.int/trachoma/epide miology/en/ adresinden erişildi. Erişim tarihi 05.05.2021

Wiersinga, W. J., Rhodes, A., Cheng, A. C., Peacock, S. J., \& Prescott, H. C. (2020). Pathophysiology, transmission, diagnosis, and treatment of Coronavirus Disease 2019 (COVID-19): A review. JAMA - Journal of the American Medical Association, 324, 782-793. https://doi.org/10.1001/jama.2020.12839

Yuki, K., Fujiogi, M., \& Koutsogiannaki, S. (2020). COVID-19 pathophysiology: A review. Clinical Immunology, 215, 1-7.
Lepelletier, D., Grandbastien, B., Romano-Bertrand, S., Aho, S., Chidiac, C., Géhanno, J. F., \& Chauvin, F. (2020). What face mask for what use in the context of the COVID-19 pandemic? The French guidelines. Journal of Hospital Infection, 105(3), 414 418. https://doi.org/10.1016/j.jhin.2020.04.036

Li, T., Liu, Y., Li, M., Qian, X., \& Dai, S. Y. (2020). Mask or no mask for COVID-19: A public health and market study. Plos One, 15(8), 1-17. https://doi.org/10.1371/journal.pone.0237691

Mahase, E. (2020, July). Covid-19: What do we know about "long covid"? The BMJ, 370, 1-2. https://doi.org/10.1136/bmj.m2815

Mheidly, N., Fares, M. Y., Zalzale, H., \& Fares, J. (2020). Effect of face masks on interpersonal communication during the COVID-19 Pandemic. Frontiers in Public Health, 8, 1-6. https://doi.org/10.3389/fpubh.2020.582191

Ngo, H., VanderLaan, D. P., \& Aitken, M. (2020). Self-esteem, symptom severity, and treatment response in adolescents with internalizing problems. Journal of Affective Disorders, 273, 183191. https://doi.org/10.1016/j.jad.2020.04.045

Okkay, İ., \& Bal, F. (2021). Covid-19 sürecinde yüz maskesi kullanmanın yüz yüze iletişime yansımaları. The Journal of Social Science, 9, 260-268. https://doi.org/10.30520/tjsosci.875614

Scheid, J. L., Lupien, S. P., Ford, G. S., \& West, S. L. (2020). Commentary: Physiological and psychological impact of face mask usage during the Covid-19 pandemic. International Journal of Environmental Research and Public Health, 17, 1-12. https://doi.org/10.3390/ijerph17186655

Secord, P. F., \& Jourard, S. M. (1953). The appraisal of bodycathexis: body-cathexis and the self. Journal of Consulting Psychology, 17(5), 343-347. https://doi.org/10.1037/h0060689 